\title{
Polypeptide expression in prostate hyperplasia and prostate adenocarcinoma
}

\author{
Ayodele Alaiya $^{\mathrm{a}, *}$, Uwe Roblick ${ }^{\mathrm{a}}$, \\ Lars Egevad $^{\mathrm{e}}$, Adelaide Carlsson ${ }^{\mathrm{b}}$, Bo Franzén ${ }^{\mathrm{a}}$, \\ Daniela Volz $^{c}$, Sören Huwendiek ${ }^{a}$, Stig Linder ${ }^{d}$ \\ and Gert Auer ${ }^{\text {a }}$ \\ ${ }^{\text {a } U n i t ~ o f ~ C a n c e r ~ P r o t e o m i c s, ~ D e p a r t m e n t ~ o f ~ O n c o l o g y ~}$ \\ and Pathology, Cancer Center Karolinska, Karolinska \\ Institute and Hospital, S-171 76 Stockholm, Sweden \\ b Sabbatsbergs Hospital, Olivecronas väg 1, S-113 24 \\ Stockholm, Sweden \\ ${ }^{\mathrm{c}}$ Department of Urology, Karolinska Institute and \\ Hospital, S-171 76 Stockholm, Sweden \\ ${ }^{\mathrm{d}}$ Radiumhemmets Research Laboratory, Department \\ of Oncology and Pathology, Cancer Center \\ Karolinska, Karolinska Institute and Hospital, S-171 \\ 76 Stockholm, Sweden \\ e Department of Pathology and Cytology, \\ Radiumhemmet, Karolinska Hospital, S-171 76 \\ Stockholm, Sweden
}

Received March 2000

Accepted 4 October 2000

Cells were collected from prostate hyperplasias $(n=6)$ and prostate carcinomas $(n=6)$ and subjected to twodimensional gel electrophoresis (2-DE). The resulting polypeptide patterns were analysed with the PDQUEST computer software. Malignant tumors showed significant increases in the level of expression of proliferating cell nuclear antigen (PCNA), calreticulin, HSP 90 and pHSP 60, oncoprotein $18(\mathrm{v})$, elongation factor 2, glutathione-S-transferase $\pi$ (GST- $\pi$ ), superoxide dismutase and triose phosphate isomerase. In addition, decreases in the levels of tropomyosin-1 and 2 and cytokeratin 18 were observed in prostate carcinomas compared to prostate hyperplasias. This pattern of alterations is similar to that observed in other carcinomas in our previous studies. All malignant tumors showed simultaneous alterations in 5 or more of 9 markers studied, whereas only one case of benign hyperplasia showed alterations in

\footnotetext{
${ }^{*}$ Corresponding author: Ayodele Alaiya, Unit of Cancer Proteomics, Department of Oncology-Pathology, Cancer Center Karolinska, CCK R8:04, Karolinska Hospital, S-171 76 Stockholm, Sweden. Tel.: +46 85177 5249; Fax: +46 8321047.
}

5 markers. The EST-data base for prostate tumors available from NCI (CGAP) was searched for the expression of the mRNAs corresponding to proteins identified in our gels. Large differences in the relative expression of mRNAs and proteins were observed. Our data show alterations in the pattern of polypeptide expression in prostate carcinomas which are similar to those observed in other carcinomas.

Keywords: Prostate cancer, two-dimensional gel electrophoresis, prognostic markers

\section{Introduction}

Carcinoma of the prostate is the most commonly diagnosed cancer in men. Prostate carcinoma provides a wide spectrum for risk of death from the disease and clinicians have long sought methods to predict the outcome accurately in individual patients. Traditional prognostic factors, such as histologic grade and stage, remain valuable. Additional clinical and laboratory studies may add to the precision of predicting the natural history of the disease or response to therapy. DNA ploidy and S-phase fraction have been studied on radical prostatectomy specimens and appear to be valuable markers for progression and recurrence of disease $[5,8,9,18]$. Immunostaining for p53 has been suggested to be an independent predictor of disease progression after radical prostatectomy [4], but reports in the litterature are conflicting [7]. Decreased E-cadherin expression has also been associated with poor prognosis [17]. New methods to define pretreatment prognosis may assist clinicians in making therapeutic choices for prostate carcinoma.

The proteome is the expressed protein complement of a genome and proteomics is functional genomics at the protein level [3,6,13]. Proteomics can be divided into expression proteomics, the study of global changes in protein expression, and cell-map proteomics, the study of protein-protein interactions through the isolation of protein complexes. Twodimensional gel electrophoresis and mass spectrometry, coupled with searches in protein and EST databases, are the main tools in proteomics. 
Proteome analyses of malignant prostate tumors and prostate hyperplasia may lead to the identification of novel prognostic markers. The aim of the present study was to use the technique of two-dimensional gel electrophoresis (2-DE) to characterize the pattern of polypeptide expression in prostate hyperplasia and prostate cancer.

\section{Materials and methods}

\subsection{Tumor tissue samples}

Samples preparation and solubilization of the tumors described in Table 1 was performed essentially as previously described [11]. Briefly, all tumors were first examined by a pathologist in order to obtain representative, viable tissue. One part of the tissue was used for preparation for 2-DE and the adjacent tissue was formailin-fixed and paraffin embedded for histological characterization. Cells were collected from the cut surface of non-necrotic tumor tissue by scraping with a sharp scalpel. Cells were collected in 2-5 ml of ice-cold RPMI-1640 medium containing 5\% fetal calf serum and $0.2 \mathrm{mM}$ phenylmethylsulphonyl fluoride/0.83 mM benzamidine. A two-phase nylon mesh filter with 250 and $100 \mu \mathrm{m}$ pore size was used to remove tissue fragments and connective tissue. Cell suspensions were underlaid with $2 \mathrm{ml}$ of ice-cold Percoll (54.7\% in PBS) and centrifuged at $1000 \mathrm{~g}$ for $10 \mathrm{~min}$ at $+4{ }^{\circ} \mathrm{C}$. Cells at the interface were collected with a syringe and washed twice with PBS. Extracts were then prepared for 2-DE analysis as described [11].

\subsection{Characterization of formalin fixed specimens}

Histopathological characterization was carried out using hematoxylin-eosin stained sections of formalin fixed and paraffin embedded specimens. Tumors were classified using the Gleason grading system [14].

\subsection{Electrophoresis}

2-DE was performed by standard procedures as previously described [11]. Resolyte (2\%, $\mathrm{pH} 4-8, \mathrm{BDH})$ were used for isoelectric focusing, 10-13\% linear gradient SDS-polyacrylamide gels were used in the second dimension. Gels were stained with silver nitrate as described by Rabilloud et al. [16].

\subsection{Identification of polypeptides}

The identification of various polypeptides in 2-DE patterns has been described previously [10]. Identification was performed by matching with published maps, exchanging samples with other investigators, by coelectrophoresis of purified proteins or by mass spectrometry. Proliferating cell nuclear antigen (PCNA) was identified by immunoblotting (PC10 mAb, Dakopatt) using a semidry system (Multiphor II Nova Blot, Pharmacia Biotech $\mathrm{AB}$ ) and ECL detection (Amersham).

\subsection{Scanning and image analysis}

2-DE gels were scanned at $100 \mu \mathrm{m}$ resolution using a Molecular Dynamics laser densitometer. Data was analyzed using PDQUEST ${ }^{\mathrm{TM}}$ software [12] obtained from Pharmacia Biotech (Uppsala, Sweden). An "identification reference pattern" was constructed ("matchset"). In subsequent analyses, polypeptide spots were matched to spots in the reference pattern using the PDQUEST $^{\mathrm{TM}}$ software. Background was subtracted, peaks located and the individual polypeptide quantities were expressed as ppm of the total integrated optical density.

\section{Results}

\subsection{Examination of expression levels of multiple polypeptide in prostate hyperplasia and in prostate carcinoma}

Cells from patients with prostate hyperplasia $(n=6)$ and prostate carcinoma $(n=6)$ were analyzed by 2-DE. The histopathological characteristics of the various cases are presented in Table 1. Cells were prepared as previously described [11] and subjected to twodimensional gel electrophoresis (representative gel shown in Fig. 1). Polypeptide patterns were analyzed by PDQUEST ${ }^{\mathrm{TM}}$ software [12] and the levels of individual polypeptides expressed as PPM.

\subsection{Expression of marker polypeptides}

Previous studies have shown that the levels of some polypeptides varies between benign and malignant breast tumors [10] and benign and malignant ovarian 
Table 1

Clinical characteristics of samples

\begin{tabular}{|c|c|c|c|c|}
\hline Sample & Diagnosis & Differentiation & Gleason score & $\overline{\text { Age/year }}$ \\
\hline UP-01 & Prostate carcinoma & Moderately/highly differentiated adenocarcinoma & $4+4$ & 77 \\
\hline UP-06 & Prostate carcinoma & Moderately/highly differentiated adenocarcinoma & $5+4$ & 63 \\
\hline UP-15 & Prostate carcinoma & Moderately/highly differentiated adenocarcinoma & $4+4$ & 73 \\
\hline UP-18 & Prostate carcinoma & Moderately/highly differentiated adenocarcinoma & $3+4$ & 76 \\
\hline UP-34 & Prostate carcinoma & Moderately/highly differentiated adenocarcinoma & $3+3$ & 56 \\
\hline UP-35 & Prostate carcinoma & Moderately/highly differentiated adenocarcinoma & $3+3$ & 53 \\
\hline UP-10 & Benign prostatic hyperplasia (BPH) & & & 64 \\
\hline UP-26 & Benign prostatic hyperplasia (BPH) & & & 61 \\
\hline UP-27 & Benign prostatic hyperplasia (BPH) & & & 74 \\
\hline UP-28 & Benign prostatic hyperplasia (BPH) & & & 80 \\
\hline UP-29 & Benign prostatic hyperplasia (BPH) & & & 67 \\
\hline UP-37 & Benign prostatic hyperplasia (BPH) & & & 76 \\
\hline
\end{tabular}

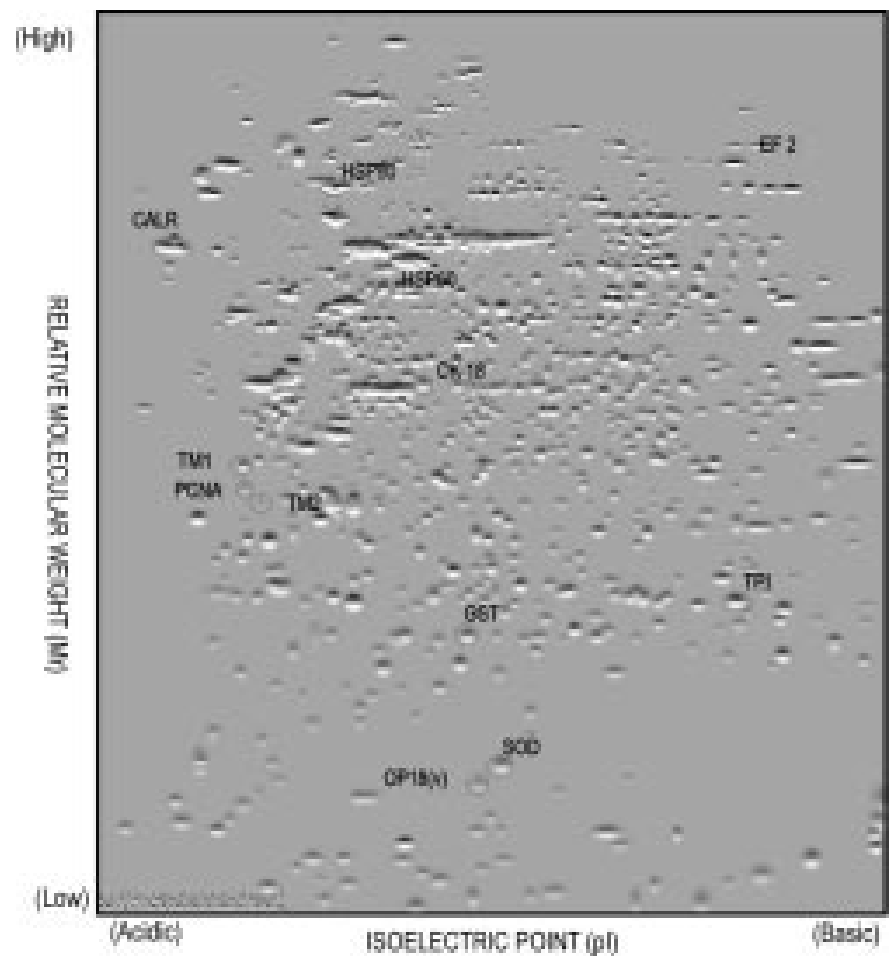

Fig. 1. Two-dimensional gel analysis of cells isolated from benign prostate hyperplasia. Some spots with known identity have been encircled.

tumors [1]. The corresponding spots could be identifed in the prostate 2-DE maps by gel matching (encircled in Fig. 1; see Section 2). Similar changes in the expression of these polypeptides were observed in prostate tumors (Fig. 2). All malignant tumors showed a greater than two-fold increase in the level of expression of proliferating cell nuclear antigen (PCNA), calreticulin, HSP90 and the phosphorylated form of HSP60, oncoprotein $18(\mathrm{v})$, elongation factor 2 , glutathione-S- transferase $\pi$, superoxide dismutase and triose phosphate isomerase. In addition, decreases in the levels of tropomyosin-1 and - 2 and a decrease of cytokeratin 18 were observed in prostate carcinomas. Despite the low number of cases, these differences were statistically significant $(P<0.05 \mathrm{MW})$. Data are summarized in Table 2.

Proteins showing qualitative and quantitative differences in their level of expression between prostate hy- 

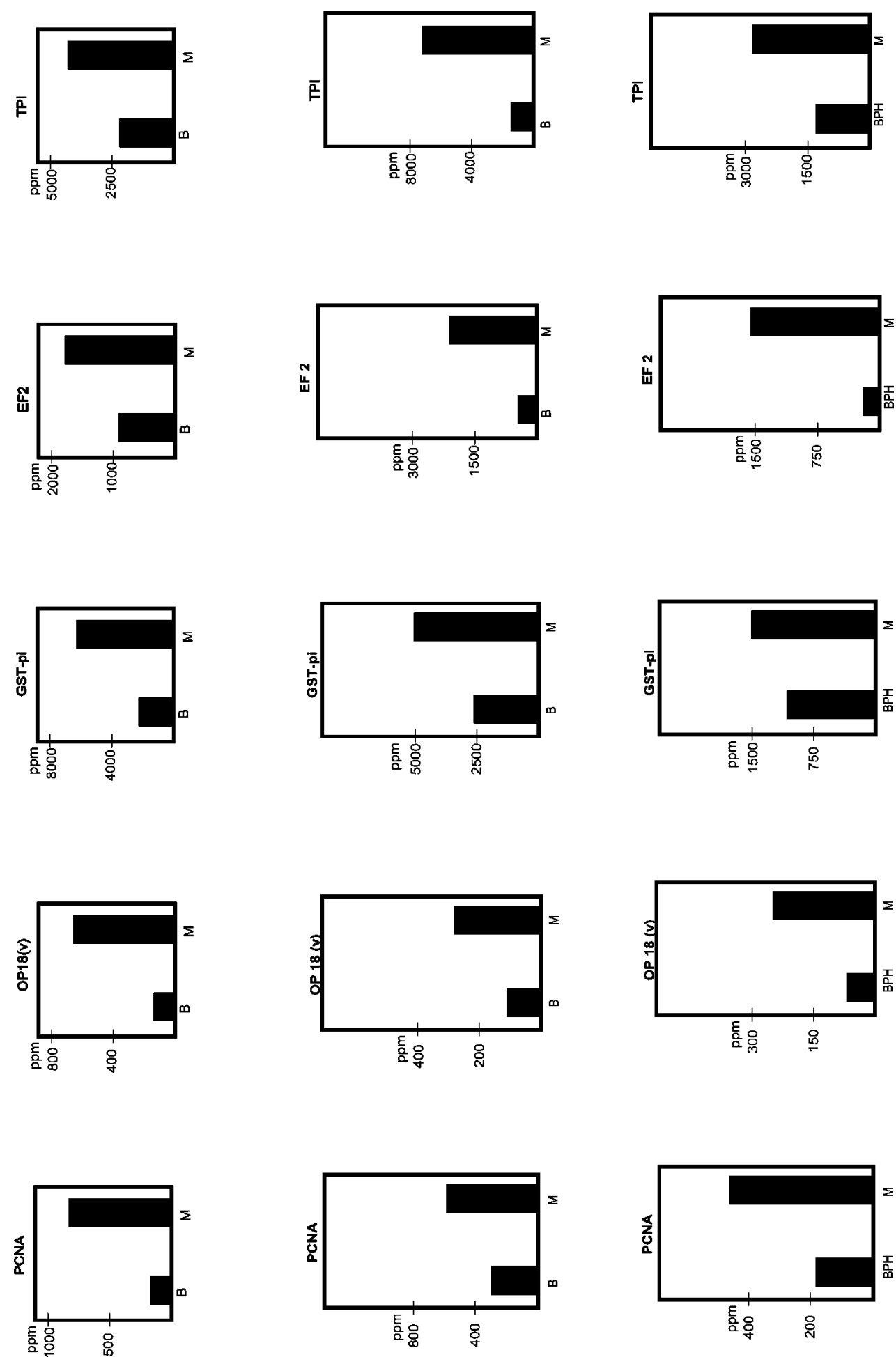

iseәдg

КјелO

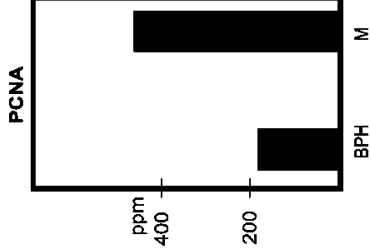

칵이d

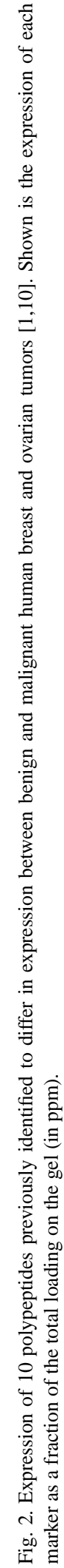



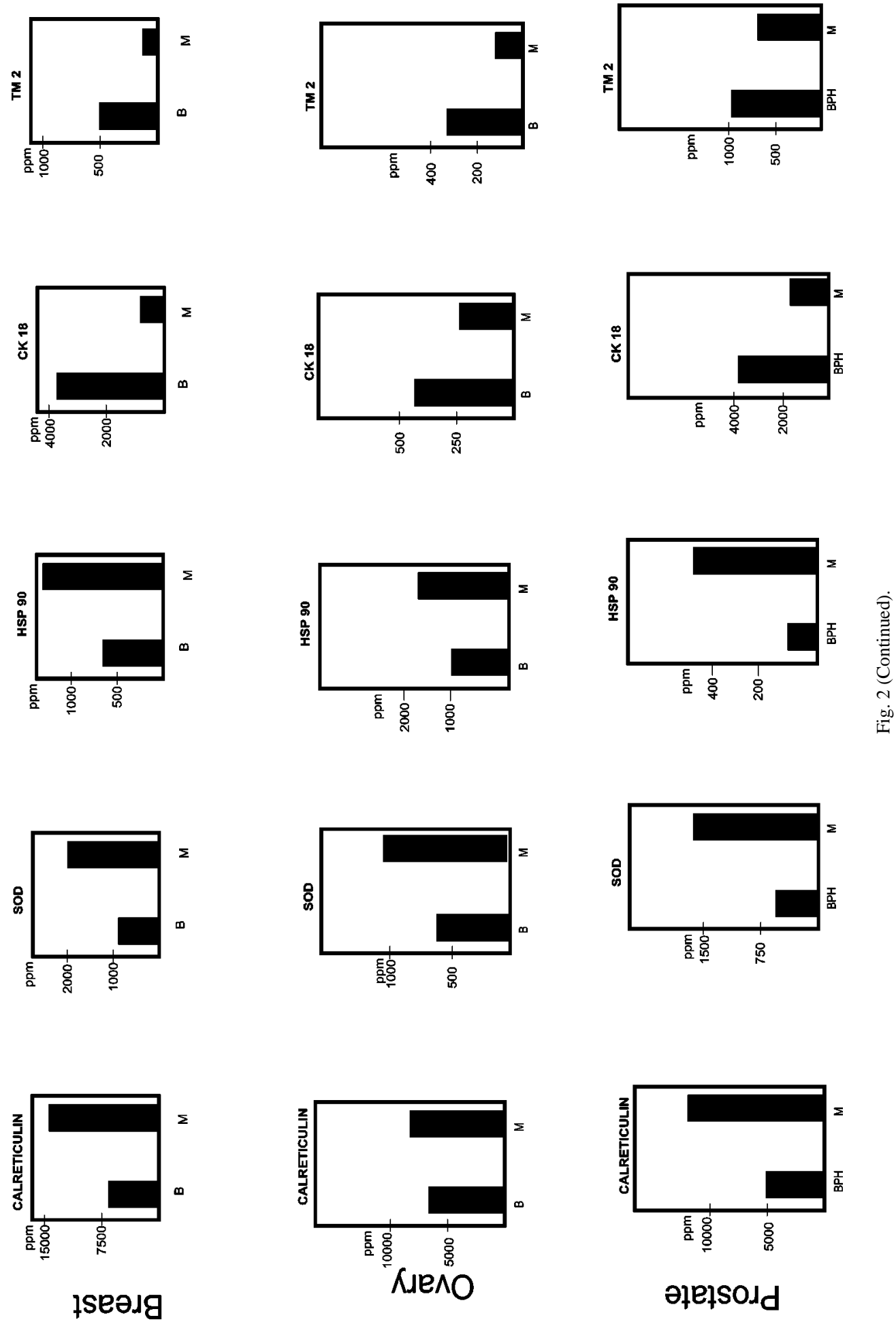
Table 2

Protein and mRNA expression levels in selected analysed polypeptides with known identity

\begin{tabular}{|c|c|c|c|c|c|c|}
\hline \multirow[t]{2}{*}{ Abbreviation } & \multirow[t]{2}{*}{ Name } & \multirow[t]{2}{*}{$\mathrm{Mr}(\mathrm{kD}) / \mathrm{pI}$} & \multicolumn{2}{|c|}{$\begin{array}{c}\text { Fold change PCA: } \\
\text { BPH }\end{array}$} & \multicolumn{2}{|c|}{$\begin{array}{c}\text { Relative expression leve } \\
\text { in PCA }(\%)\end{array}$} \\
\hline & & & Protein level & mRNA level* & Protein & mRNA* $^{*}$ \\
\hline PCNA & Proliferating cell nuclear antigen & $34.6 / 4.86$ & $2.5: 1.0$ & - & 0.05 & - \\
\hline OP $18(v)$ & Oncoprotein 18 variant & $16.7 / 5.5$ & 4.1:1.0 & $1.5: 1$ & 0.03 & - \\
\hline GST- $\pi$ & Glutathione S- transferase & $25.1 / 5.44$ & $1.5: 1.0$ & $1.1: 1$ & 0.15 & 0.08 \\
\hline EF 2 & Elongation factor & $103.0 / 6.9$ & $8.0: 1.0$ & $1.1: 1$ & 0.16 & 0.006 \\
\hline TPI & Triose Phosphate Isomerase & $27.1 / 6.53$ & $2.2: 1.0$ & $1: 6.6$ & 0.29 & 0.02 \\
\hline CALR & Calreticulin & $68.0 / 4.0$ & 2.3:1.0 & $1.2: 1$ & 1.18 & 0.06 \\
\hline SOD & Superoxide dismutase & $22.2 / 6.72$ & $2.7: 1.0$ & - & 0.16 & 0.006 \\
\hline HSP 90 & Heat shock protein & $90.9 / 5.21$ & 4.3:1.0 & $1.4: 1$ & 0.04 & 0.05 \\
\hline CK 18 & Cytokeratin 18 & $47.9 / 5.40$ & $1.0: 1.9$ & $1: 3.9$ & 0.50 & 0.15 \\
\hline TM 2 & Tropomyosin 2 & $36.3 / 4.88$ & 1.0:1.4 & $1: 2.8$ & 0.07 & 0.04 \\
\hline TM 1 & Tropomyosin 1 & $39.7 / 4.82$ & $1.0: 2.4$ & - & 0.03 & - \\
\hline PHSP 60 & Phosphorylated heat shock protein 60 & $56.0 / 5.21$ & 2.3:1.0 & - & 0.27 & - \\
\hline
\end{tabular}

* CGAP home page.

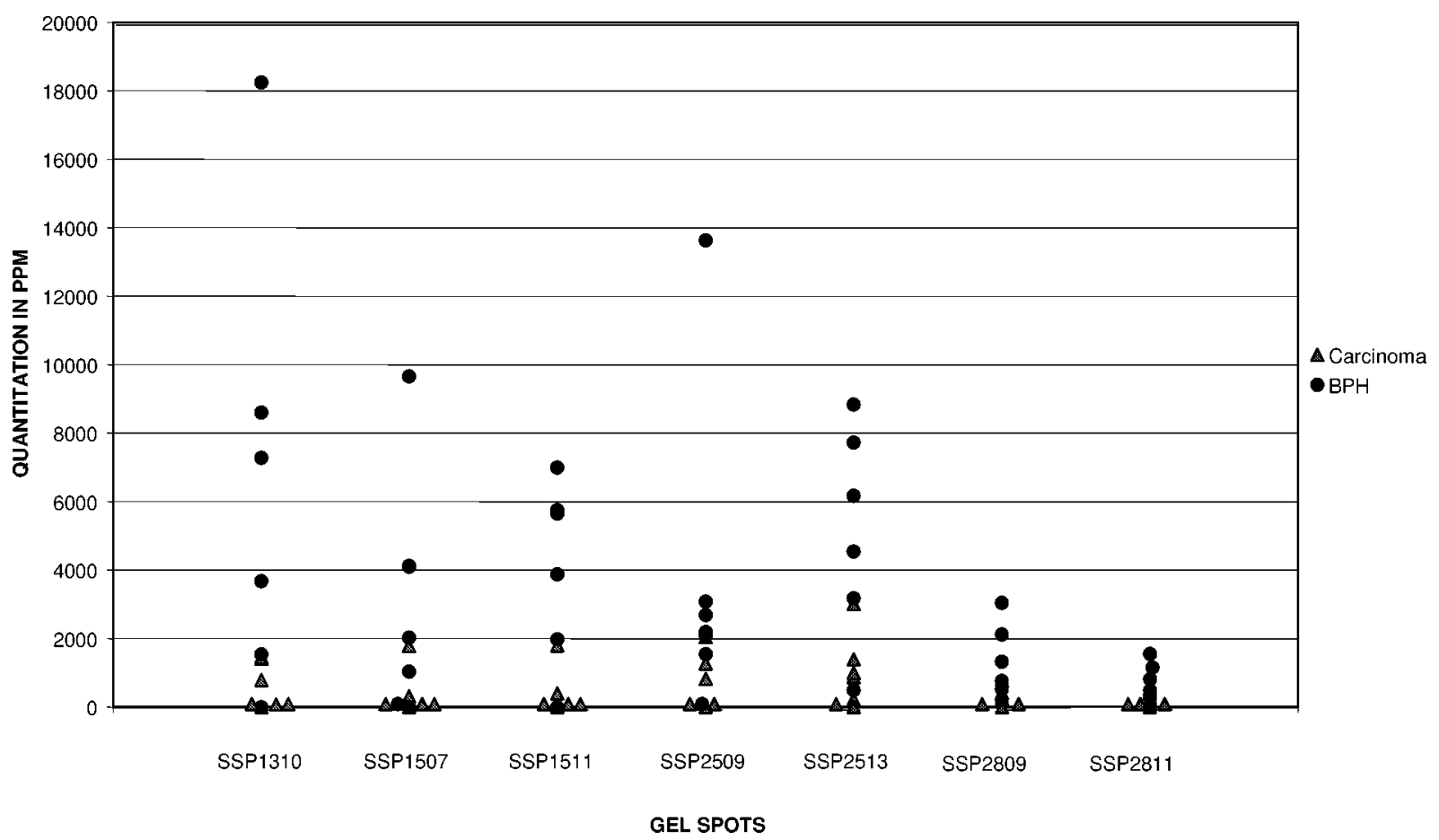

Fig. 3. Expression of 20 spots with significant $(p<0.05)$ differences between prostate hyperplasia and cancer. The expression level of each individual case is indicated.

perplasias and carcinomas were identified. When all the matched spots among individual gels were examined, twenty polypeptides showed more than 2-fold increases between carcinomas and benign prostate hyperplasias (Fig. 3). Due to the limited amount of clinical material available, it was not possible to obtain sequence information from these polypeptides.
Cut-off levels of the expression of 9 polypeptide markers have previously been defined in ovarian cancer, based on the expression of these polypeptides in benign and malignant cells [1]. We used these cut-off levels and examined the pattern of expression of this set of 9 markers in each prostate tumor (Fig. 4, see legend for details). All six carcinomas showed the malig- 


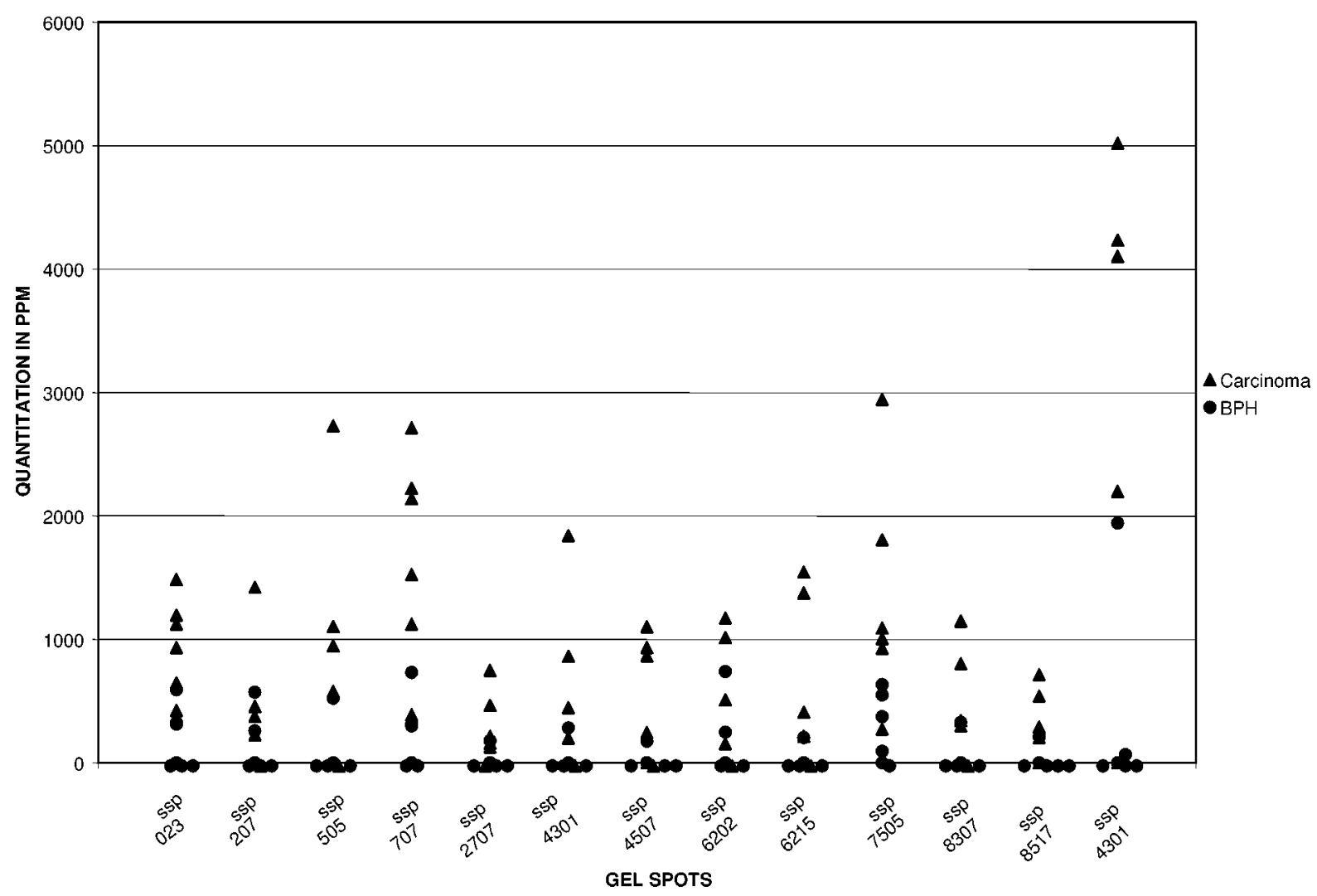

Fig. 3. (Continued)

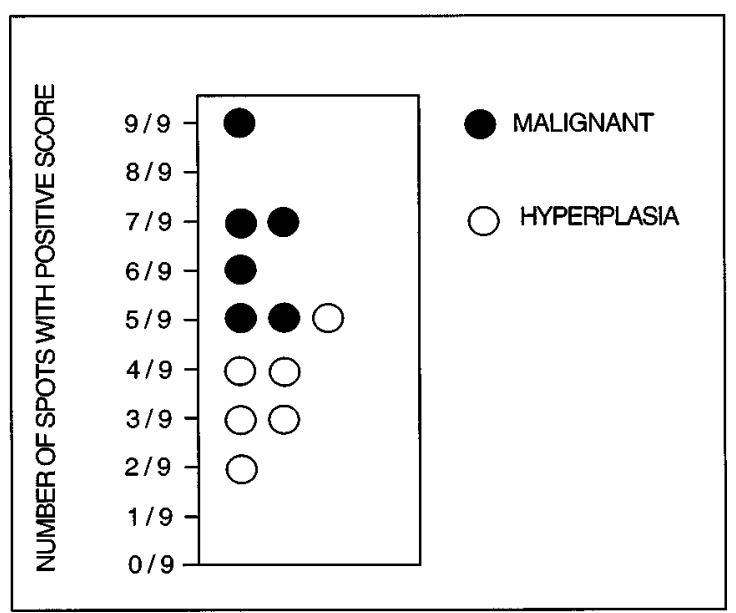

Fig. 4. Scores of the expression of 9 different protein markers in individual tumors. Cut-off values for the classification of expression of each markers to be negative or positive have been previously established for ovarian carcinoma [1], and the same cut-offs were used here. The number of proteins expressed in each tumor at levels beyond the cut-off level are indicated (9/9 meaning that all proteins were expressed beyond the cut-off level). The 9 proteins were PCNA, TM-1, TM-2, calreticulin, HSP-60, HSP-90, cytokeratin 18, TPI and elongation factor 2.

nant pattern of expression of 5 or more of the 9 markers. By contrast, only 1 benign tumor showed the malignant pattern of expression of 5 markers.
The abundance of mRNA transcripts can be evaluated by random sequencing of cDNA clones. Data from the NCI Cancer Gene Anatomy Project (CGAP) 


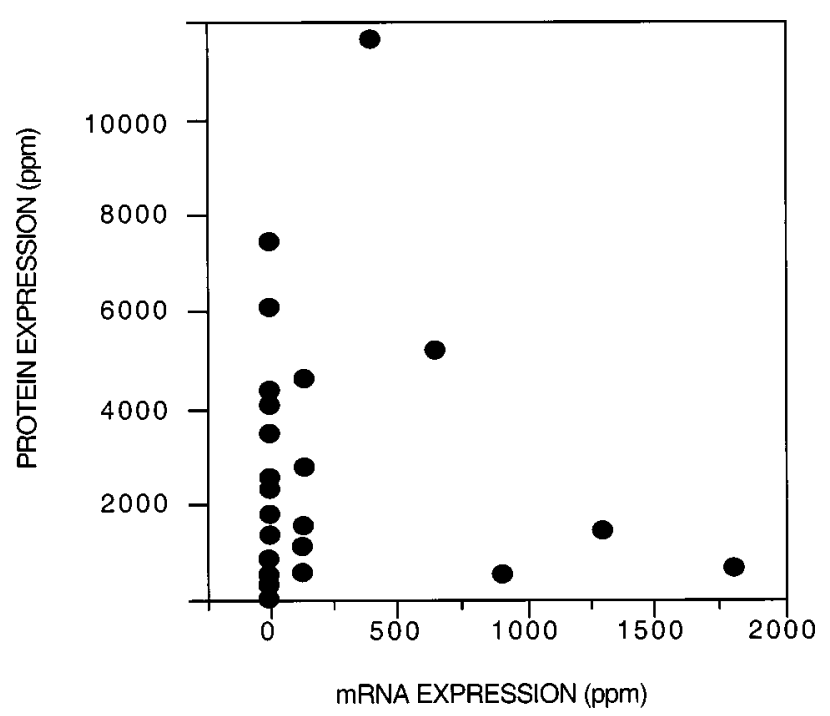

Fig. 5. Relationship between protein and mRNA expression levels of a number of genes expressed in prostate carcinomas. On the $y$-axis, the protein expression levels are plotted (as ppm of totally loaded protein on 2-DE gels, average of 6 gels from prostate carcinoma). On the $x$ - axis, the representation of the same gene products in cDNA libraries are plotted (as ppm, number of hits per 7747 cDNA clones in 3 prostate carcinoma libraries).

is available at the web-site http://www.ncbi.nlm.nih. gov/ncicgap/. In the CGAP data base, cDNA sequence information from 3 libraries constructed from microdissected prostate carcinomas are presented (libs $283,513,527$; total of 7747 sequences). We compared the abundance of mRNA transcripts in these 3 libraries and the abundance of the corresponding proteins in the six cases of prostate carcinoma. The results are presented in Table 2 and Fig. 5. There was no apparent correlation between the abundance of proteins in the 2-DE patterns and their occurence in the libraries.

\section{Discussion}

We have previously established methods which can be used to obtain high quality polypeptide maps from human tumor material and have now examined the pattern of protein expression in prostate tumors. A set of polypeptides found to be differentially expressed in malignant versus benign breast and ovarian tumors were also found to be differentially expressed in malignant prostate tumors compared to prostatic hyperplasia. The expression of the cell cycle regulated PCNA and OP18 proteins, the stress proteins calreticulin, HSP60 and HSP90 were increased in malignant tumors. Similarly, SOD, elongation factor-2 (EF-2) and triose phosphate isomerase were increased. We observed decreases in the levels of tropomyosin-1 and -2 in all carcinomas compared to benign prostatic hyperplasia. Prasad and coworkers [15] previously showed a progressive loss of expression of tropomyosin isoforms and myosin light chain- 2 during prostate tumor progression. As summarized in Fig. 2, the levels of all these proteins were found to be similarly affected in malignant breast, ovarian and prostate tumors, suggesting a high degree of homology in the expression of these proteins among different tumor types of epithelial origin.

We previously established cut-off values for a set of 9 polypeptides and were able to classify ovarian tumors into benign/borderline/malignant [1]. We used the same cut-off values for prostate tumors, and found that the pattern of expression of the 9 polypeptides could be used to classify the tumors (Fig. 4). The use of more refined statistical methods such as principal component analysis and the identification of additional marker polypeptides is likely to result in a more precise classification. We are currently working along those lines.

The protein and mRNA abundance levels were quite different for some gene products expressed in prostate carcinomas. There are several possible explanations for this result. It may reflect a true biological situation with large differences in the turn-over of different proteins, leading to high levels of proteins encoded by lowly abundant mRNAs. The number of clones sequenced so far in the Cancer Gene Anatomy Project 
is limited $(<10,000$ cDNA clones from prostate carcinomas), leading to uncertainties in the estimation of mRNA frequencies. It is also possible that the frequencies of different clones in the cDNA libraries are, for various reasons, not proportional to the frequencies of the mRNAs. Finally, it is possible that some estimates of protein abundancies are incorrect due to comigration of proteins in the same spots. We conclude that protein and cDNA analyses of gene expression may not necessarily give the same results and that both approaches are therefore warranted.

Anderson and Seilhamer [2] reported that the mRNA abundancies for highly expressed liver proteins were much lower than the protein abundance. Furthermore, the cDNAs of weakly expressed proteins were often not found in the libraries. In their analysis, a correlation coefficient of 0.48 was obtained, compared to 0.0079 in this study. The reason for the weaker correlation between protein and mRNA expression in the tumor material analysed here, compared to normal liver, is not clear.

In conclusion, we have developed methods to obtain good quality 2D maps from prostate tumors and identified tumor-related protein expression patterns comprising both known and unknown proteins. These proteins may possibly be used for diagnosis of human prostate tumors.

\section{Acknowledgements}

We are grateful to Ms. Ann Ohlsson, Ms. Kicki Svanholm, Ms. Birgitta Sundelin and Ms. Inga Maurin for technical assistance. This work was supported by Cancerföreningen i Stockholm and by Cancerfonden.

\section{References}

[1] A.A. Alaiya, B. Franzén, K. Fujioka, B. Moberger, K. Schedvins, C. Silversvärd, S. Linder and G. Auer, Phenotypic analysis of ovarian carcinoma: polypeptide expression in benign, borderline and malignant tumors, Int. J. Cancer 73 (1997), 678-683.

[2] L. Anderson and J. Seilhamer, A comparison of selected mRNA and protein abundancies in human liver, Electrophoresis 18 (1997), 533-537.

[3] N.L. Anderson and N.G. Anderson, Proteome and proteomics: new technologies, new concepts, and new words, Electrophoresis 19 (1998), 1853-1861.
[4] J.J. Bauer, T.A. Sesterhenn, K.F. Mostofi, D.G. McLeod, S. Srivastava and J.W. Moul, p53 nuclear protein expression is an independent prognostic marker in clinically localized prostate cancer patients undergoing radical prostatectomy, Clin. Cancer Res. 1 (1995), 1295-1300.

[5] M.C. Bettencourt, J.J. Bauer, I.A. Sesterhenn, F.K. Mostofi, D.G. McLeod and J.W. Moul, Ki-67 expression is a prognostic marker of prostate cancer recurrence after radical prostatectomy [see comments], J. Urol. 156 (1996), 1064-1068.

[6] P. Bork, T. Dandekar, Y. Diaz-Lazcoz, F. Eisenhaber, M. Huynen and Y. Yuan, Predicting function: from genes to genomes and back, 283 (1998), 707-725.

[7] J.D. Brooks, G.S. Bova, C.M. Ewing, S. Piantadosi, B.S. Carter, J.C. Robinson, J.I. Epstein and W.B. Isaacs, An uncertain role for p53 gene alterations in human prostate cancers, Cancer Res. 56 (1996), 3814-3822.

[8] L. Bubendorf, G. Sauter, H. Moch, H.P. Schmid, T.C. Gasser, P. Jordan and M.J. Mihatsch, Ki67 labelling index: an independent predictor of progression in prostate cancer treated by radical prostatectomy, J. Pathol. 178 (1996), 437-441.

[9] G. Forsslund, P.L. Esposti, B. Nilsson and A. Zetterberg, The prognostic significance of nuclear DNA content in prostatic carcinoma, Cancer 69 (1992), 1432-1439.

[10] B. Franzén, G. Auer, A.A. Alaiya, E. Eriksson, K. Uryu, T. Hirano, K. Okuzawa and S. Linder, Analysis of polypeptide expression in benign and malignant human breast lesions: downregulation of cytokeratins, Br. J. Cancer 73 (1996), 1632-1638.

[11] B. Franzén, K. Okuzawa, S. Linder, H. Kato and G. Auer, Non-enzymatic extraction of cells from clinical tumour material for analysis of gene expression by two-dimensional gel electrophoresis, Electrophoresis 14 (1993), 382-390.

[12] J.I. Garrels, The QUEST system for quantitative analysis of two-dimensional gels, J. Biol. Chem. 264 (1989), 5269-5282.

[13] D.F. Hochstrasser, Proteome in perspective, Clinical Chemistry \& Laboratory Medicine 36 (1998), 825-836.

[14] D.F. Gleason and G.T. Mellinger, Prediction of prognosis for prostatic adeno-carcinoma by combined histological grading and clinical staging, J. Urol. 111 (1974), 58-64.

[15] S.C. Prasad, P.J. Thraves, A. Dritschilo and M.R. Kuettel, Protein expression changes associated with radiation-induced neoplastic progression of human prostate epithelial cells, Electrophoresis 18 (1997), 629-637.

[16] T. Rabilloud, L. Vuillard, C. Gilly and J.-J. Lawrence, Silver-staining of proteins in polyacrylamide gels: A general overview, Cell Mol. Biol. 40 (1994), 57-75.

[17] R. Umbas, W.B. Isaacs, P.P. Bringuier, H.E. Schaafsma, H.F. Karthaus, G.O. Oosterhof, F.M. Debruyne and J.A. Schalken, Decreased E-cadherin expression is associated with poor prognosis in patients with prostate cancer, Cancer Res. 54 (1994), 3929-3933.

[18] L. Åström, A. Weimarck, F. Aldenborg, U. Delle, C. Hanson, I. Verbiene, A. Danielsson, J. Hammarsten and I. Kopf, Sphase fraction related to prognosis in localised prostate cancer. No specific significance of chromosome 7 gain or deletion of 7q31.1, Int. J. Cancer 79 (1998), 553-559. 


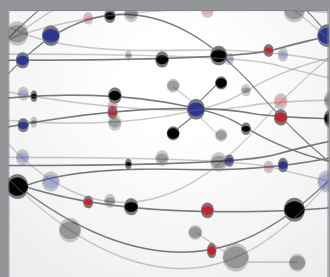

The Scientific World Journal
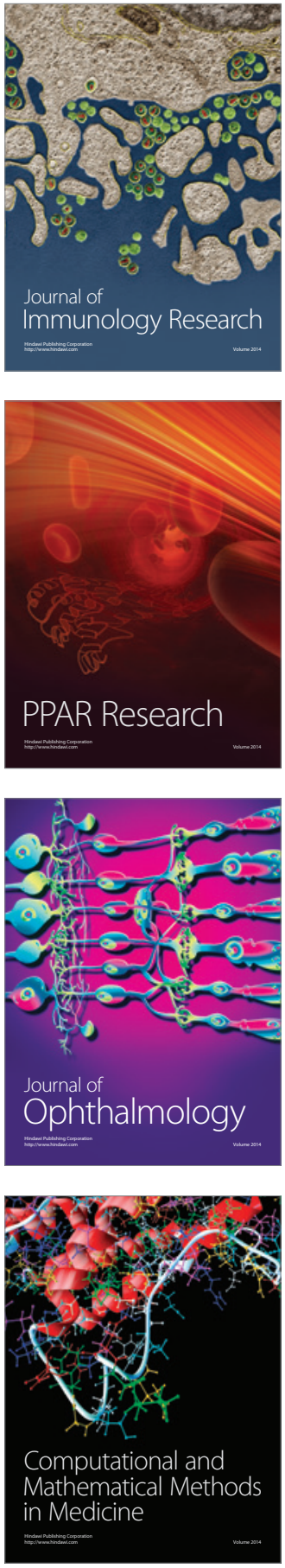

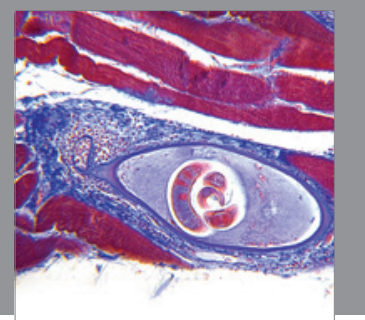

Gastroenterology

Research and Practice
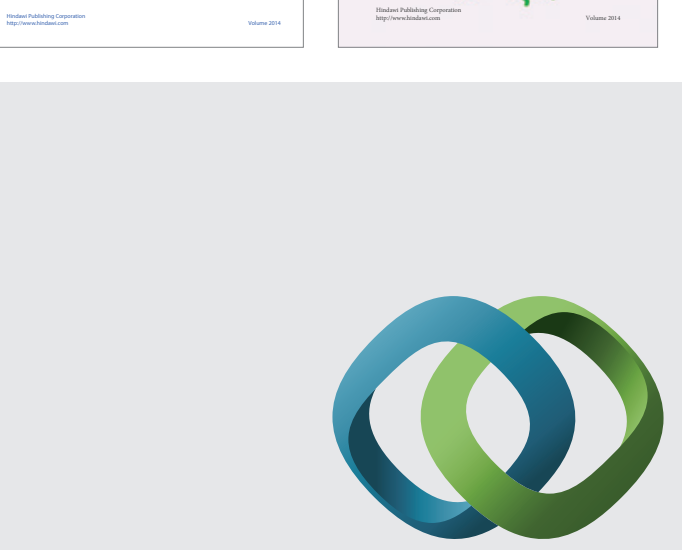

\section{Hindawi}

Submit your manuscripts at

http://www.hindawi.com
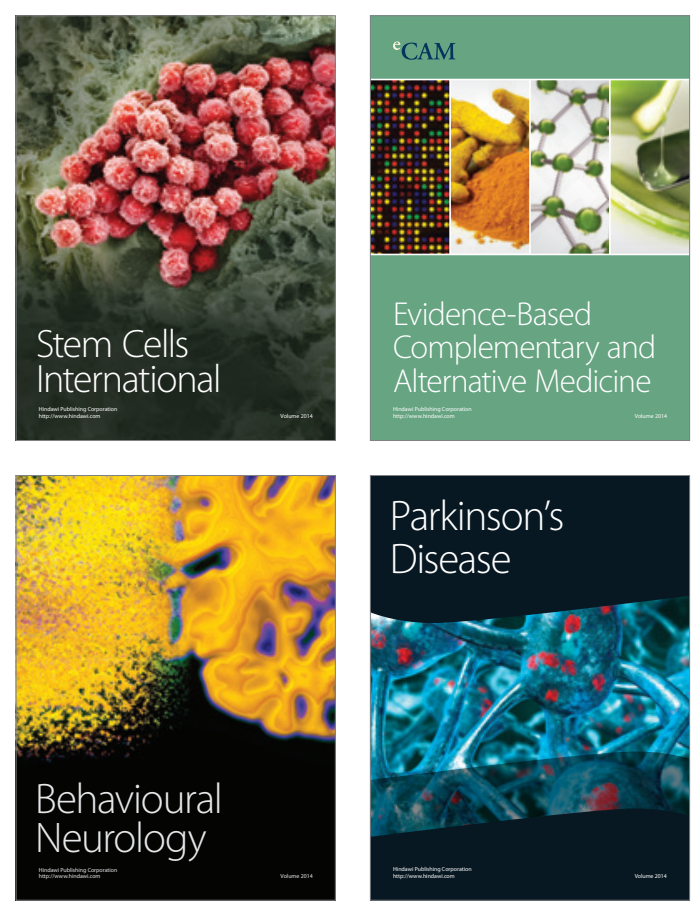

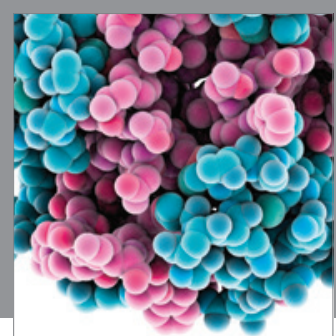

Journal of
Diabetes Research

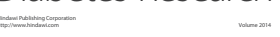

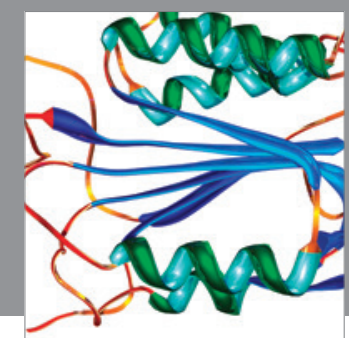

Disease Markers
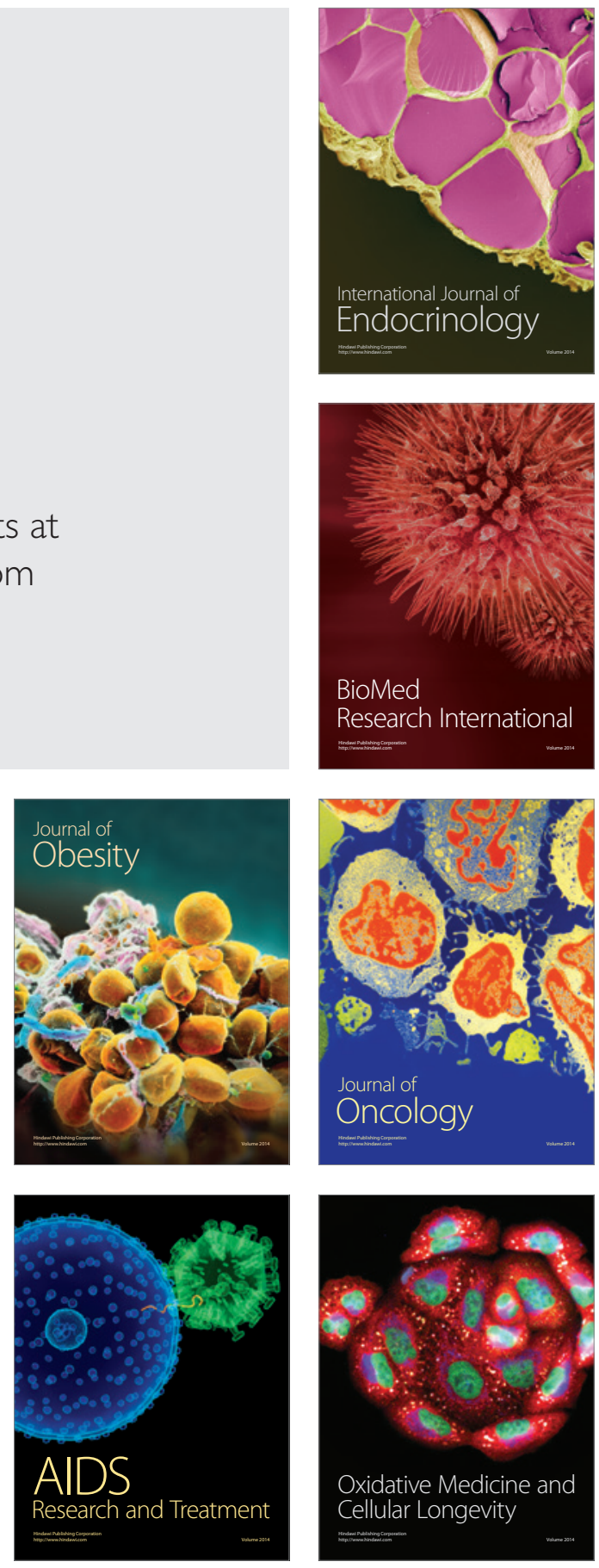